\title{
Perinatal outcomes of severe preeclampsia/ eclampsia and associated factors among mothers admitted in Amhara Region referral hospitals, North West Ethiopia, 2018
}

\author{
Misganaw Fikirie Melese, Marta Berta Badi and Getie Lake Aynalem*
}

\begin{abstract}
Objective: This study was aimed to assess perinatal outcomes of severe preeclampsia/eclampsia and associated factors among mothers admitted in Amhara Region referral hospitals, North West Ethiopia, 2018.

Results: This study revealed that the overall prevalence of unfavorable perinatal outcome from the severe preeclamptic/eclamptic mothers was $46.5 \%$. It shows that the finding of unfavorable perinatal outcome was high which needs an obligation to put our recommendation as improvement of health care set ups for preventions as well as interventions of such problems. Variables which were positively associated with unfavorable perinatal outcomes were: maternal educational status ( $A O R=6.6,95 \% \mathrm{Cl} 1.32,10.03)$, parity $(A O R=8.3,95 \% \mathrm{Cl} 6.27,27.02)$, gestational age in weeks ( $A O R=9.6,95 \% \mathrm{Cl} 2,18.65$ ) and time of drug given for the mother $(\mathrm{AOR}=3.8,95 \% \mathrm{Cl} 1.81,8.07)$.
\end{abstract}

Keywords: Perinatal, Outcomes, Severe preeclampsia and eclampsia, Ethiopia

\section{Introduction}

Preeclampsia: is the new onset of hypertension and proteinuria after 20 weeks of gestation in a previously normotensive woman $[1,2]$. Severe preeclampsia is a serious clinical type of preeclampsia manifested by at least one of the followings: persistent increase in blood pressure $(\geq 160 / 110 \mathrm{mmHg})$, hepatic or renal failure, platelet count $<100,000 / \mathrm{mm}^{3}$, hemolytic elevated liver enzymes and low platelet count (HELLP) syndrome, cerebral or visual disturbances, persistent severe epigastric pain and pulmonary edema [3].

Eclampsia is a serious obstetric emergency with new onset of grand mal seizure during pregnancy or postpartum in a woman having signs or symptoms of preeclampsia [4-7].

The sequel of severe preeclampsia and eclampsia includes organ failure, loss of consciousness and finally loss of lives of both mother and fetus $[4,8,9]$. A

*Correspondence: motherliving54@gmail.com

School of Midwifery, University of Gondar, Gondar, Ethiopia systematic review for epidemiology of preeclampsia reviewed by USA investigators states that pregnancy induced hypertension remains a leading cause of maternal and perinatal morbidity and mortality worldwide [10]. Another study carried out in Mettu Karl referral hospital to assess maternal and perinatal outcomes of severe preeclampsia and eclampsia indicated that $12 \%$ of perinatal mortality [11]. The Government of Ethiopia in line with WHO takes a commitment to reduce perinatal mortalities through multiple high impact interventions at both facility and community levels to remove bottlenecks such as harmful traditional practices, poor infrastructure, shortage of transportation facilities and inadequate care at health facilities that can hamper access to safe motherhood services [12]. Even though, there were devotion to reduce pregnancy related complications and mortalities, perinatal deaths due to severe preeclampsia/eclampsia is still increasing worldwide [7, 13, 14].

According to different perspectives from different countries mentioned above showed that the burden of severe preeclampsia/eclampsia is not only limited to 
maternal health problem, but also significant number of fetal deaths [15-17].

Studies tried to investigate the trend, magnitude and associated factors of severe preeclampsia and eclampsia throughout the world [7, 14, 18-21], but almost all these studies used secondary data and limited to investigate feto-maternal outcomes.

This study, therefore, was conducted to determine the perinatal outcomes of severe preeclampsia and eclampsia by incorporating time of drug initiation in addition to the variables of the previous studies used.

\section{Main text}

\section{Methods}

\section{Study design and setting}

Institutional based cross-sectional study was conducted among 456 severe preeclamptic and eclamptic mothers from April 1 to September 30, 2018. The setting was in referral hospitals of Amhara Region, North West Ethiopia. This regional state has 67 hospitals among which 5 are referrals that is: University of Gondar Teaching Referral Hospital, Felege Hiwot Referral Hospital, Dessie referral hospital, Debremarkos referral hospital, and Debrebirhan referral hospital. Three of them were selected with a lottery method (Felege-Hiwot Referral Hospital, Debre-Markos Referral Hospital and Dessie Referral Hospital).

\section{Sample size and sampling procedures}

The sample size was determined by counting the 2017, severe preeclampsia and eclampsia cases for 6 months preceded the data collection time in the logbooks of randomly selected referral hospitals of Amhara Region. According to these logbooks, Felege-Hiwot Referral Hospital, Debre-Markos Referral Hospital and Dessie Referral Hospital have 174, 138 and 102 severe preeclamptic/ eclamptic cases from October 1/2017 to March 30/2018 (the preceded 6 months of data collection) respectively. The sample size we used was the total cases of the three referral hospitals which was totaled as 414 we added a $10 \%$ expected non-response rate which became 456 .

We used census to get enough sample size and we have gone with data collection until our sample size was saturated from each of the referral hospitals according to their case flows.

\section{Operational definitions}

Perinatal complication of severe preeclampsia Complications of the newborn due to severe preeclampsia and eclampsia including low birth weight, still birth, intra uterine growth restriction, intra uterine fetal death, preterm birth, low APGAR score, birth asphyxia and abortus [2].
Favorable perinatal outcome Newborns from severe preeclampic and eclampic mothers end up without perinatal complications of severe preeclampsia and eclampsia [11].

Unfavorable perinatal outcome Newborn from severe preeclampic and eclampic mothers ended up with at least one complication of severe preeclampsia and eclampsia $[11,20]$.

Low APGAR score Apgar score less than 7 in either or both 1 st and 5 th min of delivery.

\section{Data collection procedures and tools}

Data were collected using a semi-structured, pre-tested and interview based questionnaire adapted from the literatures. It was prepared in English and translated into local language Amharic and finally returned to English by English language expertise. Nine midwives were involved in the data collection process.

\section{Data quality control}

Semi-structured data collection tool was utilized and clarity of the tool was tested before the final utilization. The pretest was conducted among $5 \%$ of the sample size in Debre Berhan referral hospital. A 1 day training was given for data collectors and supervisors regarding the objectives of the study, data collection method and significance of the study. During data collection each data collector was supervised for any difficulties and directions and necessary corrections were provided.

\section{Data processing and analysis}

All collected data were rechecked for completeness, coded and entered using Epi Info 7.2, and exported to SPSS version 23 for cleaning and analysis. Bivariable logistic regression was employed to identify association, and multivariable logistic regression model was used to control the effect of confounders.

Variables having P-value less than 0.05 in the Bivariable analysis were fitted into the multivariable logistic regression model. 95\% CI and odds ratio were computed and variables having $\mathrm{P}$-value less than 0.05 in the multivariable logistic regression analysis were considered to declare statistical significance. Descriptive statistics like frequencies and cross tabulation was performed.

\section{Results}

\section{Socio-demographic characteristics}

A total of 456 cases were included in the study among which, two hundred forty-three (53.3\%) were severe preeclamptic and two hundred thirteen (46.7\%) eclamptic. 
The mean age of the participants was 28.3 years. As per educational status of the participants, 193 (42.3\%) responded that they were unable to read/write. Most of the respondents, 429 (94.1\%) were married. More than half of the participants, 235 (51.5\%) were urban dwellers (Table 1).

\section{Obstetrical characteristics}

Greater than half of the participants, 261 (57.2\%) were Multiparas. The median gestational age of the respondents was 38 weeks, ranging from 21 to 43 weeks. Half of respondents, 225 (49.4\%) gestational age was found to be between 37 and 40 weeks. More than two-third of the participants, 315 (69.1\%) had ANC follow up. Threefourth of the respondents, 346 (75.9\%) had no history of abortion. Nearly two-third of participants, 292 (64\%) with severe preeclampsia and eclampsia were unbooked in the referral hospitals of Amhara Region. Mode of deliveries were: - $172(37.7 \%)$ vaginally after induction/ augmentation, 136 (29.8\%) SVD and 127 (27.9\%) C/S.

\section{Time of treatment and drugs given}

Greater than half of the respondents, 267 (58.6\%) had received medications lately (after they developed complications) where as 189 (41.4\%) of them had got early (as soon as severe preeclampsia/eclampsia was diagnosed). Magnesium sulfate and Methyl dopa were the most frequently administered anti-convulsing and anti-hypertensive, drugs administered for 431 (94.5\%) and 395 (86.6\%) respondents respectively.

\section{Perinatal outcomes of severe preeclampsia and eclampsia}

Two hundred twelve (46.5\%) newborns delivered from respondents were ended up with unfavorable outcomes of severe preeclampsia and eclampsia with $95 \% \mathrm{CI}$ $(42.2 \%, 51.1 \%)$ and nearly one-third of the fetuses, 103 (28.1\%) were still births (Table 2).

\section{Factors associated with the response variable}

Bivariate analysis showed that: maternal educational status, monthly family income, maternal residence, parity, gestational age in weeks, maternal booking status and Time of drugs given were crudely associated.

Independently and positively associated variables in adjusted analysis were: maternal educational status, parity, gestational age in weeks and time of drugs given (Table 3).

\section{Discussion}

This institutional based cross sectional study has attempted to assess the perinatal outcomes of severe pre-eclampsia/eclampsia and associated factors among
Table 1 Socio-demographic characteristics among mothers with severe preeclampsia and eclampsia admitted, in Amhara region referral hospitals, North West Ethiopia, $2018(n=456)$

\begin{tabular}{|c|c|c|}
\hline Variables & Frequency & Percent \\
\hline \multicolumn{3}{|l|}{ Maternal age } \\
\hline Age $\leq 19$ & 33 & 7.3 \\
\hline Age 20-35 & 349 & 76.5 \\
\hline Age $\geq 36$ & 74 & 16.2 \\
\hline \multicolumn{3}{|l|}{ Religion } \\
\hline Orthodox & 347 & 76.1 \\
\hline Muslim & 101 & 22.2 \\
\hline Protestant & 7 & 1.5 \\
\hline Catholic & 1 & 0.2 \\
\hline \multicolumn{3}{|l|}{ Marital status } \\
\hline Married & 429 & 94.1 \\
\hline Single & 20 & 4.4 \\
\hline Divorced & 4 & 0.9 \\
\hline Widowed & 3 & 0.7 \\
\hline \multicolumn{3}{|l|}{ Educational status } \\
\hline Unable to read and write & 193 & 42.3 \\
\hline Able to read/write & 38 & 8.3 \\
\hline Elementary & 56 & 12.3 \\
\hline Secondary & 71 & 15.6 \\
\hline College and above & 98 & 21.5 \\
\hline \multicolumn{3}{|l|}{ Occupation } \\
\hline Unemployed & 16 & 3.5 \\
\hline Housewife & 281 & 61.6 \\
\hline Private worker & 76 & 16.7 \\
\hline Governmental worker & 66 & 14.5 \\
\hline $\mathrm{NGO}$ & 6 & 1.3 \\
\hline Student & 11 & 2.4 \\
\hline \multicolumn{3}{|l|}{ Residence } \\
\hline Urban & 235 & 51.5 \\
\hline Rural & 221 & 48.5 \\
\hline \multicolumn{3}{|l|}{ Traditional treatment use } \\
\hline Yes & 268 & 58.8 \\
\hline No & 188 & 41.2 \\
\hline \multicolumn{3}{|l|}{ Monthly family income in USA dollar } \\
\hline Income $<72.8$ USA dollar & 226 & 49.6 \\
\hline Income from 72.8 to 125.2 USA dollar & 95 & 20.8 \\
\hline Income > 125.2 USA dollar & 135 & 29.6 \\
\hline
\end{tabular}

women admitted in Amhara Region referral hospitals, North West Ethiopia, 2018.

The study results showed that the prevalence of unfavorable perinatal outcomes was $46.5 \%$ which is lower than a 5 years period cross sectional study in Addis Ababa town (66.4\%). This difference might be due time gap as time goes, there is a likelihood of better health care system. 
Table 2 Cause of perinatal outcomes of severe preeclampsia and eclampsia among mothers admitted in Amhara Region referral hospitals, North West Ethiopia, $2018(n=456)$

\begin{tabular}{|c|c|c|}
\hline \multirow{3}{*}{ Fetal outcomes } & \\
\hline & \multirow{2}{*}{$\begin{array}{l}\text { Favorable } \\
\text { Unfavorable }\end{array}$} & \multirow{3}{*}{$\begin{array}{r}244(53.5 \%) \\
212(46.5 \%) \\
\text { Percent (\%) }\end{array}$} \\
\hline & & \\
\hline Cause of unfavorable outcomes & Frequency & \\
\hline LBW & 59 & 13 \\
\hline Low APGAR score & 49 & 10.8 \\
\hline IUGR & 20 & 4.4 \\
\hline Stillbirth & 103 & 22 \\
\hline Preterm birth & 49 & 10.8 \\
\hline Birth asphyxia & 46 & 10.1 \\
\hline Abortus & 41 & 8.9 \\
\hline
\end{tabular}

Stillbirth was one of the causes for unfavorable outcomes. 103 (22.6\%) of newborns were stillbirths which is a higher finding compared with the studies done in Addis Ababa (8.5\%) [14], Mettu Karl Referral Hospital (10.2\%), Ghana (6.8\%) [20] and Haiti (17.8\%) [17] but lower than studies done in Nigeria (34.2\%). It shows that stillbirth is still high which may alert policy makes, managers and health care providers to make health care set up better.

Forty-one $(8.9 \%)$ of the pregnancies from severe preeclamptic/eclamptic mothers were ended up with abortion which is in line with a 3 years retrospective cross sectional study done on 121 cases in Mettu Karl Referral Hospital, Ethiopia (10.7\%). This finding compared with Mettu Karl Referral Hospital has better implication because they used secondary data but ours is primary

Table 3 Binary and Multivariable logistic regression results of factors associated with perinatal outcomes of severe preeclampsia and eclampsia among women admitted in Amhara region referral hospitals, North West Ethiopia from April 1 to September 30, $2018(n=456)$

\begin{tabular}{|c|c|c|c|c|}
\hline \multirow[t]{2}{*}{ Variables } & \multicolumn{2}{|c|}{ Fetal outcome } & \multirow[t]{2}{*}{ COR $(95 \% \mathrm{Cl})$} & \multirow[t]{2}{*}{ AOR $(95 \% \mathrm{Cl})$} \\
\hline & Unfavorable & Favorable & & \\
\hline \multicolumn{5}{|l|}{ Educational status } \\
\hline Unable to read and write & 117 & 76 & $7.9(4.29,14.49)^{* *}$ & $6.6(1.32,10.03)^{*}$ \\
\hline Read and write & 20 & 17 & $6.0(2.60,13.96)^{* *}$ & $4.6(1.18,12.01)^{*}$ \\
\hline Elementary school & 32 & 26 & $6.3(2.99,13.28)^{* *}$ & $4.3(1.33,13.63)^{*}$ \\
\hline Secondary school & 27 & 43 & $3.2(1.56,6.61)$ & $2.8(0.89,8.79)$ \\
\hline College and above & 16 & 82 & 1 & 1 \\
\hline \multicolumn{5}{|l|}{ Monthly family income } \\
\hline Income $<72.8$ USA dollar & 140 & 86 & $8.4(4.922,14.20)$ & $2.1(0.84,5.05)$ \\
\hline Income from 72.8 to 125.2 USA dollar & 50 & 45 & $5.7(3.10,10.49)$ & $2.4(0.86,6.45)$ \\
\hline Income > 125.2 USA dollar & 22 & 113 & 1 & 1 \\
\hline \multicolumn{5}{|l|}{ Residence } \\
\hline Rural & 145 & 75 & $4.8(3.25,7.21)$ & $1.3(0.61,2.70)$ \\
\hline Urban & 67 & 168 & 1 & 1 \\
\hline \multicolumn{5}{|l|}{ Parity } \\
\hline Nully para & 59 & 11 & $10.5(5.27,21.07)^{* *}$ & $8.3(6.27,27.02)^{*}$ \\
\hline Premipara & 64 & 58 & $2.2(1.40,3.36)^{*}$ & $5.2(4.15,13.97)^{*}$ \\
\hline Multi para & 89 & 175 & 1 & 1 \\
\hline \multicolumn{5}{|l|}{ Gestational age in weeks } \\
\hline GA 20-27 & 38 & 3 & $4.9(1.38,17.39)^{*}$ & $9.6(2.00,18.65)^{*}$ \\
\hline GA 28-36 & 76 & 7 & $4.2(1.69,10.40)^{*}$ & $5.4(1.98,14.73)^{*}$ \\
\hline GA $37-40$ & 33 & 190 & $0.1(0.03,0.12)^{* *}$ & $0.2(0.08,0.36)^{* *}$ \\
\hline $\mathrm{GA}>41$ & 62 & 24 & 1 & 1 \\
\hline \multicolumn{5}{|l|}{ Booking status } \\
\hline Unbooked & 184 & 108 & $8.27(5.16,13.25)$ & $1.84(0.86,3.93)$ \\
\hline Booked & 28 & 136 & 1 & 1 \\
\hline \multicolumn{5}{|l|}{ Time of drug given } \\
\hline Late & 178 & 89 & $9.1(5.81,14.29)^{* *}$ & $3.8(1.81,8.07)^{* *}$ \\
\hline Early & 34 & 155 & 1 & 1 \\
\hline
\end{tabular}

** P-value $<0.001,{ }^{*}$ P-value $<0.05,1=$ reference 
data, their study population was all hypertensive cases but ours is only severe preeclamptic/eclamptic cases.

LBW (16.1\%), low APGAR score (13.4\%), IUGR (5.4\%), preterm birth (13.4\%) and birth asphyxia (12.5\%) were other causes of unfavorable perinatal outcomes of the study which each is lower than the studies done in Mettu Karl Referral Hospital (low birth weight of 30.5\%, and low APGAR score of $18.5 \%$, and preterm delivery $31.4 \%$ ), Debre Berhan Referral Hospital, Ethiopia (39.4\% low birth weight, 38.4\% low APGAR score and 8.5\% IUGR) and Iran (52.6\% preterm, 9.9\% IUGR and $17.3 \%$ LBW) [22]. The difference could be due to time gap.

One of the predictor variables for perinatal outcomes of severe preeclampsia-eclampsia was maternal educational status. Newborns from mothers who were with educational status of unable to read/write, able to read/ write and elementary school were more likely to develop unfavorable perinatal outcomes compared with those mothers who were with educational status of college and above with the odds ratio of (AOR $=6.6,95 \% \mathrm{CI} 1.32$, $10.03)(\mathrm{AOR}=4.6,95 \% \mathrm{CI} 1.18,12.01)(\mathrm{AOR}=4.3,95 \%$ CI $1.33,13.63)$ respectively.

It shows that the higher the women`s educational status is, the lower the perinatal unfavorable outcomes of severe preeclampsia/eclampsia. It could be due to the fact that as educational status is good, the mothers are likely to improve their health care seeking behaviors including having adequate ante-natal care follow up which can improve the perinatal outcomes.

Parity was another predictor variable. Newborns delivered from nully and primi paras women were more likely to develop unfavorable perinatal outcomes when compared with multi paras women with the odds ratio of $(\mathrm{AOR}=8.3,95 \% \mathrm{CI} 6.27,27.02)$ and $(\mathrm{AOR}=5.2,95 \%$ CI $4.15,13.97)$ respectively. This finding is in line with studies done in South East Nigeria [21]. It might be due to the fact that frequency and severity of preeclampsiaeclampsia is more common in nully paras and primi paras which may possibly affect the perinatal outcomes.

Gestational age was also associated with the outcome variable. Pregnancies interrupted from 20 to 27 and 28 to 36 completed weeks were with high unfavorable perinatal outcomes when compared with pregnancies terminated from 37-40 weeks with the odds ratio of $(\mathrm{AOR}=9.6,95 \% \mathrm{CI} 2.00,18.65)$ and $(\mathrm{AOR}=5.4,95 \%$ CI $1.98,14.73)$ respectively. And when pregnancies terminated from 37 to 40 weeks compared with pregnancies terminated at 41 and above weeks, it shows $80 \%$ less likely to develop the unfavorable perinatal outcomes (AOR $=0.2,95 \% \mathrm{CI} 0.08,0.36)$. It shows the favorable gestational age of pregnancy termination in severe preeclamptic-eclamptic mothers is from 37 to 40 weeks. These findings are supported by a study conducted in Mettu Karl Referral Hospital, Ethiopia [11]. This could be related with prematurity in early weeks and placental apoptosis in late weeks which both possibly affect the perinatal outcomes.

Additional variable that positively predicts the perinatal outcomes of severe preeclampsia-eclampsia was time of drugs given. Newborns delivered from severe preeclamptic-eclamptic mothers who were provided anticonvulsing and anti-hypertensive drugs lately were more likely to develop unfavorable perinatal outcomes than the mothers received these drugs early (AOR $=3.8,95 \%$ CI 1.81, 8.07). It puts a recommendation of giving drugs early.

\section{Limitations}

Long term perinatal complications were not addressed and we might be in fear of the nature of cross-sectional design.

\section{Abbreviations \\ ANC: ante natal care; HEELPS: hemolysis elevated liver enzymes and low plate- let count syndrome; iugr: intra uterine growth restriction; SVD: spontaneous} vaginal delivery; C/S: caesarean section.

\section{Authors' contributions}

MFM brought the idea. Then all, MFM, MBB and GLA equally contributed on proposal development, data collection process, data management and analysis, and write up. All authors read and approved the final manuscript.

\section{Acknowledgements}

We would like to thank the University of Gondar, a college of the health science, school of Midwifery for their clearance approval. We would extend our heartfelt thanks for data collectors, supervisors and study participants.

\section{Competing interests}

The authors declare that they have no competing interests.

\section{Availability of data and materials}

The datasets used and/or analyzed during the current study are available from the corresponding author on reasonable request.

\section{Consent for publication}

Not applicable because there are no individually detailed data, videos or images.

\section{Ethics approval and consent to participate}

Prior to data collection, the proposal was submitted to University of Gondar school of Midwifery Ethical Review Committee to grantee approval and Amhara regional health bureau was queried to provide permission letter Ethical clearance letter was obtained From the Ethical Review Committee of school of Midwifery of the institutional reviewer board of university of Gondar. Ethical clearance letter and formal letter also was obtained from University Gondar school of Midwifery and was submitted to Amhara Region referral hospitals and permission of each hospital was obtained from hospital administrative. Written permission letter was also received from Hospital managers and ward coordinator in the study set up. Again before the data collection, written informed consent was obtained from each participants. The purpose of the study was briefly explained to the mothers independently prior to data collection and they were informed that their participation would purely voluntary with secured confidentiality. The mothers were also informed that they had full right not to participate in or withdraw from the study. 


\section{Funding}

The article was not funded.

\section{Publisher's Note}

Springer Nature remains neutral with regard to jurisdictional claims in published maps and institutional affiliations.

Received: 23 January 2019 Accepted: 1 March 2019

Published online: 15 March 2019

\section{References}

1. Federal Ministry of Health. Management protocol on selected obstetrics topics. Federal Ministry of Health: Addis Ababa; 2010. p. 176-92.

2. Gabbe SG. Obstetrics: normal and problem pregnancies. 6th ed. Philadelphia: Saunders, an imprint of Elsevier Inc.; 2012.

3. Konar H. DC DUTTA's textbook of obstetrics. 7th ed. New Delhi: Jaypee Brothers Medical Publishers (P) Ltd; 2013.

4. Cunningham FG, Leveno JK, Bloom SL. Williams obstetrics. 24th ed. New York: McGraw-Hill Education; 2014

5. Pauli JM, Repke JT. Preeclampsia short-term and long-term implications. Obstet Gynecol Clin N Am. 2015;42:299-313.

6. Phipps E, Prasanna D, Brima W, Jim B. Preeclampsia: updates in pathogenesis, definitions, and guidelines. J Am Soc Nephrol. 2016;11(6):1102-13.

7. WHO. Trends in maternal mortality: 1990 to 2015. Geneva: WHO, UNICEF UNFPA, World Bank Group and the United Nations Population Division; 2015. p. 2015.

8. DeCherney $\mathrm{AH}$, Nathan L, Goodwin M, Laufer N. Current diagnosis \& treatment obstetrics \& gynecology. 10th ed. New York: McGraw-Hill Companies, Inc; 2007

9. Liabsuetrakul T, Thida T. Geographical distribution of hypertensive disorders in pregnancy and their adverse maternal and perinatal outcomes in Thailand. Int J Pregnancy Child Birth. 2017;2(2):42-3.

10. Legesse T, Misra Abdulahi AD. Trends and causes of maternal mortality in Jimma university specialized hospital. Int J Women's Health. 2017;9:307.

11. Wagnew M, Dessalegn M. Trend of preeclampsia/eclampsia, maternal and neonatal outcomes among women delivering in government hospitals, Addis Ababa, Ethiopia. Pan Afr Med J. 2018;25(Suppl 2):12.
12. Gaym A, Bailey P, Pearson L, Admasu K, Gebrehiwot Y, Ethiopian National Em ONCAT. Disease burden due to pre-eclampsia/eclampsia and the Ethiopian health system's response. Int J Gynaecol Obstet. 2011;115(1):112.

13. Federal Ministry of Health. Ministry of health policy and practice information for action. Addis Ababa: Federal Ministry of Health; 2014.

14. Saxena N, Bava AK, Nandanwar Y. Maternal and perinatal outcome in severe preeclampsia and eclampsia. Int J Reprod Contracept Obstet Gynecol. 2016:5(7):2171-6.

15. Raghuraman N, March MI, Hacker MR, Modest AM, Wenger J, Narcisse R, et al. Adverse maternal and fetal outcomes and deaths related to preeclampsia and eclampsia in Haiti. Pregnancy Hypertens. 2014;4(4):279-86.

16. Agrawal S, Walia GK, Staines-Urias E, et al. Prevalence of and risk factors for eclampsia in pregnant women in India. Fam Med Community Health. 2017;5(4):225-44.

17. Guerrier G, Oluyide B, Keramarou M, Grais RF. Factors associated with severe preeclampsia and eclampsia in Jahun, Nigeria. Int J Women's Health. 2013:5:509.

18. Wagnew M, Muluken D, Worku A, Nyagero J. Trends of preeclampsia/ eclampsia and maternal and neonatal outcomes among women delivering in Addis Ababa selected government hospitals, Ethiopia. Pan Afr Med J. 2016;25(2):12.

19. Terefe W, Getachew Y, Hiruye A, Derbew M, Hailemariam D, Mammo D, et al. Patterns of hypertensive disorders of pregnancy and associated factors at Debre Berhan referral hospital, North Shoa, Amhara Region. Ethiop Med J. 2015;2:57-65.

20. Adu-Bonsaffoh K, Ntumy MY, Obed SA, Seffah JD. Perinatal outcomes of hypertensive disorders in pregnancy at a tertiary hospital in Ghana. BMC Pregnancy Childbirth. 2017;17(1):388.

21. Ajah LO. The feto-maternal outcome of preeclampsia with severe features and eclampsia in Abakaliki, South-East Nigeria. J Clin Diagn Res. 2016;10(9):QC18

22. Khosravi S, Dabiran S, Lotfi M, Asnavandy M. Prevalence of hypertension and complications of hypertensive disorders in pregnancy. Open J Prev Med. 2014:4:860-7.
Ready to submit your research? Choose BMC and benefit from:

- fast, convenient online submission

- thorough peer review by experienced researchers in your field

- rapid publication on acceptance

- support for research data, including large and complex data types

- gold Open Access which fosters wider collaboration and increased citations

- maximum visibility for your research: over $100 \mathrm{M}$ website views per year

At BMC, research is always in progress.

Learn more biomedcentral.com/submissions 